\title{
Modeling and Analysis of Business Process Compliance
}

\author{
Jörg Becker ${ }^{1}$, Christoph Ahrendt ${ }^{1}$, André Coners ${ }^{2}$, \\ Burkhard Weiß ${ }^{1}$, and Axel Winkelmann ${ }^{1}$ \\ ${ }^{1}$ University of Muenster, ERCIS - European Research Center for Information Systems, \\ Leonardo-Campus 3, 48149 Muenster, Germany \\ Tel.: +49 (0) $2518338100,+49$ (0) 2518338100 , \\ +49(0) $2518338089,+49$ (0) 2518338086 \\ \{joerg.becker, burkhard.weiss, axel. \\ winkelmann\} dercis.uni-muenster.de, chris.a@uni-muenster.de \\ ${ }^{2}$ Fachhochschule Südwestfalen, Haldener Str. 182, 58095 Hagen \\ Tel.: +49 (0) 23319330717 \\ conersafh-swf.de
}

\begin{abstract}
Managing business process compliance is a highly important topic in the financial sector. Various scandals and last but not least the financial crisis have caused many new constraints and legal regulations that banks and financial institutions need to face. Based on a domain-specific semantic business process modeling notation, we propose a new approach to modeling and analysis of business process compliance through the use of compliance building block patterns and business rules. These business process compliance patterns and rules serve as a necessary basis for the automatic identification of compliance issues in existing processes (process models) and hence for managing business process compliance in the financial sector.
\end{abstract}

Keywords: Compliance, Business Process Modeling, Business Process Management, Governance, Finance.

\section{Introduction}

Although no general understanding of "compliance" exists, it can be understood as conforming to a rule such as a specification, a policy or a standardized procedure. In this context, "Business Process Compliance" (BPC) management is a new research field that addresses the coordination of business process management (BPM) and compliance (Rinderle et al. 2008). Regulations and laws force service companies to ensure compliant business processes (Basel Committee on Banking Supervision 2004). We therefore address business compliance rules for banks in this article because the automatic identification and analysis of financial sector processes, with regard to their alignment, with new compliance requirements, is still an unsolved problem.

Huge efforts are being spent on the actual modeling of business processes, but justified benefits in the analysis and usage of process models are rare (Becker et al. 2010d). It turns out that automated analysis of process models is hardly possible with 
standard business process modeling languages. Nevertheless, this is especially desirable, since many regulations have to be considered and new regulations require an ongoing analysis of business processes.

Hence, this paper aims at formalizing compliance-related business rules in a semantic way that is easily understood by compliance experts, while at the same time enabling banks to automatically check for these business rules in semantic business process models. We do this by proposing a business rule-based extension of SBPML, a semantic business process modeling notation that was developed specifically for the financial sector and represents an intuitive modeling approach for non-BPM experts (Becker et al. 2009; Becker et al. 2010b; Becker et al. 2010c; Becker et al. 2010e).

\section{State of the Art in Modeling and Analysis of Business Process Compliance}

In Information Systems Research, business rules are considered as self-contained scientific objects (Herbst and Knolmayer 1995). The core elements of the business rules approach have been determined by the BRG in their business rules manifesto (Business Rules Group 2003), which was later enhanced by OMG (Object Management Group 2006). According to Scheer and Werth (2006) they are ,[...] guidelines or business practices [...], that affect or guide the behavior of companies. Behavior means [...], with which processes (how) and with which resources (whereby), which goods are produced." They can be of internal and external origin (e.g. laws). In this context, business rules shall be regarded as normative instructional statements that are distinguished by their specifying character, related to their process execution (Hay and Healy 2000). The fundamental purpose of business rules lies in securing conformity of business processes within legal and other guidelines, as well as verification of conformity.

By means of this specification, business rules can be created and transferred to business rules management systems (BRMS) (Hoheseil 2000). Rule editors support the creation, validation and simulation of business rules by providing an appropriate development environment. These rules can subsequently be stored in a repository, which is available to form the basis for process management. These rules are particularly effective with regard to controlling processes, if they are combined with operational systems, like ERP or workflow management systems, for example, via web services that access the BRMS during execution, using the output of rule analysis, to determine the follow-up actions (Grob et al. 2008).

With the help of business rules, process execution logic, stored in operative systems, can be transferred into BRMS and can be stored independently from its type and place of future application (Endl 2004). This allows advantages in flexibility, so that modifications of business rules in the operating departments are possible, for example, in order to adapt to changing conditions, like legal formalities. Furthermore, a centralized storage of control logic avoids the problem of a variety of different implementations of the same business rules in different application systems. Business processes have to provide valid and consistent control logic, in order to enable purposeful execution of processes and to avoid process anomalies on an instance level. The supervision and enforcement of these defined business rules, using BRMS, immediately intends to enforce existing (internal or external) guidelines of process instances. 
Different language constructs can be used to design business rules (Scheer and Werth 2006). One possibility is to use simple IF-THEN-rules or their derived extensions of ECA-rules (event-condition-action) or ECAA-rules (event-condition-actionalternative) (Hanson 1992). Another possibility is the Business Process Compliance Language (BPCL) (Wörzberger et al 2008), which defines inclusion, precedence and existence conditions for business rules. However, all of these constructs can only partially be applied to very different types of business rules (not just regarding process control flows, but also business objects used in a process, as well as resources), not all of them are easily understood by business process compliance officers (e.g. BPCL) and all of these only support semantic interpretation on a very abstract level, since a predefined ontology for a domain-specific vocabulary is missing.

According to El Kharbili et al. (2008a) and El Kharbili et al. (2008b), successful BPC implementation:

- requires an integrated approach, reflecting the entire BPM lifecycle,

- should support compliance verification beyond simple control flow aspects,

- needs an intuitive graphical notation for compliance requirements that is also comprehend $\neg$ ible for non-experts and

- should support the application of semantic technologies for the definition, implementation and execution of automated compliance verification.

Hence, for the purpose of BPC management, we propose to develop a semantic approach to BRM that allows for intuitive modeling and analysis of business process compliance. Since especially the last two aspects target at an easy to use semantic modeling and analysis language and our focus is on the financial sector, we will build upon the Semantic Business Process Modeling Language (SBPML) notation (Becker et al. 2009; Becker et al. 2010d; Becker et al. 2010e), which we will describe briefly next.

\section{SBPML as an Approach to Semantic Business Process Modeling and Analysis}

SBPML was originally developed since researchers identified an inefficiency of generic process modeling languages in terms of modeling and analysis of business processes in the financial sector (Becker et al. 2010d). As a result, it focuses on an economic, domain-specific and thus semantic modeling approach, based on reusable process building blocks that are designed specifically for modeling and analysis of activities and processes in banks (Becker et al. 2009, Weiß and Winkelmann 2011).

The process modeling notation consists of four views, comprising a process view ("how is a service delivered?"), a business object view ("what is processed or produced?"), an organizational view ("who is involved in the process?") and a resource view ("what resources are used?") (cf. Figure 1). The core constructs of this language are domain-specific process building blocks (PBB), which have an integrating role by connecting all views (cf. Figure 1). A PBB represents a certain set of activities (e.g. "Enter Data into IT" or "Archive Document / Information") within an administrative process and applies a domain-specific vocabulary. PBBs are atomic, have a welldefined level of abstraction and are semantically specified by a domain concept. PBBs belong to the process view and represent the lowest abstraction level of a process 

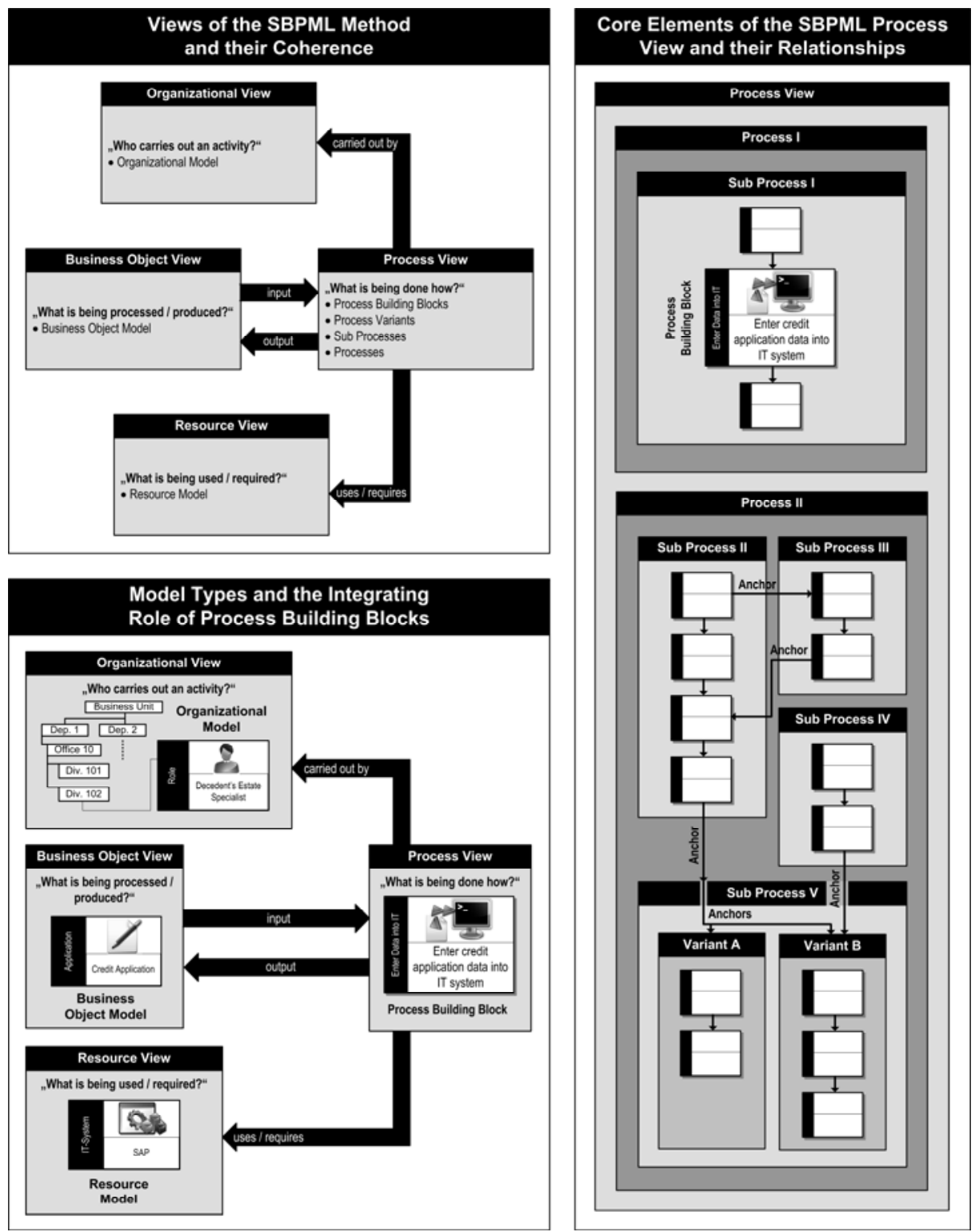

Fig. 1. SBPML Views, Model Types and Levels of Abstraction of the Process View

model. Processes are represented as a sequential flow of PBBs. PBBs are contained within different variants of sub processes. The sub processes, representing the activities of just one organizational unit, are in turn part of a larger process, which usually involves multiple organizational units and thus multiple sub processes (cf. Figure 1). Additional facts about the processes can be collected with the help of attributes (e.g. "Duration" for the PBB "Enter Data into IT"), assigned to each PBB. They establish a connection to the business object, organizational and resource view. 


\section{Developing Artifacts for Modeling Compliance-Related Business Rules in SBPML}

Through a literature review we identified business rule types that are used in the context of BPC in banks. According to Sadiq et al. (2007) they include:

- flow tags, which represent rules regarding the business process control flow and thus the execution of certain activities in a process (e.g. order of activities, existence of certain activities etc.),

- time tags, which represent rules that depict temporal conditions or restraints within process flows (e.g. maximum time that may be needed to respond to a customer request),

- resource tags, which represent rules regarding the used resources, when executing a certain activity (e.g. authorization rules for IT systems or restrictions separations of duties within a process flow) and

- data tags, which represent rules regarding the (business object) data, used throughout a process (e.g. data like the name of the credit applicant that must be contained in a credit application).

Concerning the SBPML notation, there are business rules that refer to the process view solely (flow tags and time tags), the business object view, possibly in conjunction with the process view (data tags) and the resource view, as well as the organizational view, possibly in conjunction with the process view (resource tags). Since time tags can only be evaluated during run-time and not on the level of process models, they will not be considered further. Regarding different flow tags, we follow Awad and Weske (2009), who have concentrated on identifying and describing process control flow business rules for BPMN (Business Process Modeling Notation).

According to Awad and Weske (2009), control flow business rules define the sequence, in which activities can or should be performed. Generally, predecessor relations (Activity A "leads to" Activity B) and successor relations (Activity A "precedes" Activity B) are established, but also existence (inclusion) or non-existence constraints should be depicted. In addition, depending upon an activity's position within a process or sequence of activities, different scopes can be defined. The sequence, as well as the existence or non-existence of activities, is defined within a certain "scope" of an entire process. The scope of a constraint can either be "global", or with respect to another activity "before" or "after" that activity, or with respect to two other activities between those two activities.

In Figure 2 (a) Activity A must be part of a process; in (b) Activity A may not be part of the entire process. (c) describes the classical successor constraint, (e) the predecessor constraint. In (d) Activity A may not be executed before Activity B is finished; in (f) Activity B may not be executed after Activity A is finished. (g) and (h) describe the non-existence constraint of Activity B between Activity A and Activity $\mathrm{C}$, with the difference that Activity A and Activity $\mathrm{C}$ in ( $\mathrm{g}$ ) are in a successor relationship, whereas they are in a predecessor relationship in (h) (cf. Becker et al. 2010a). 


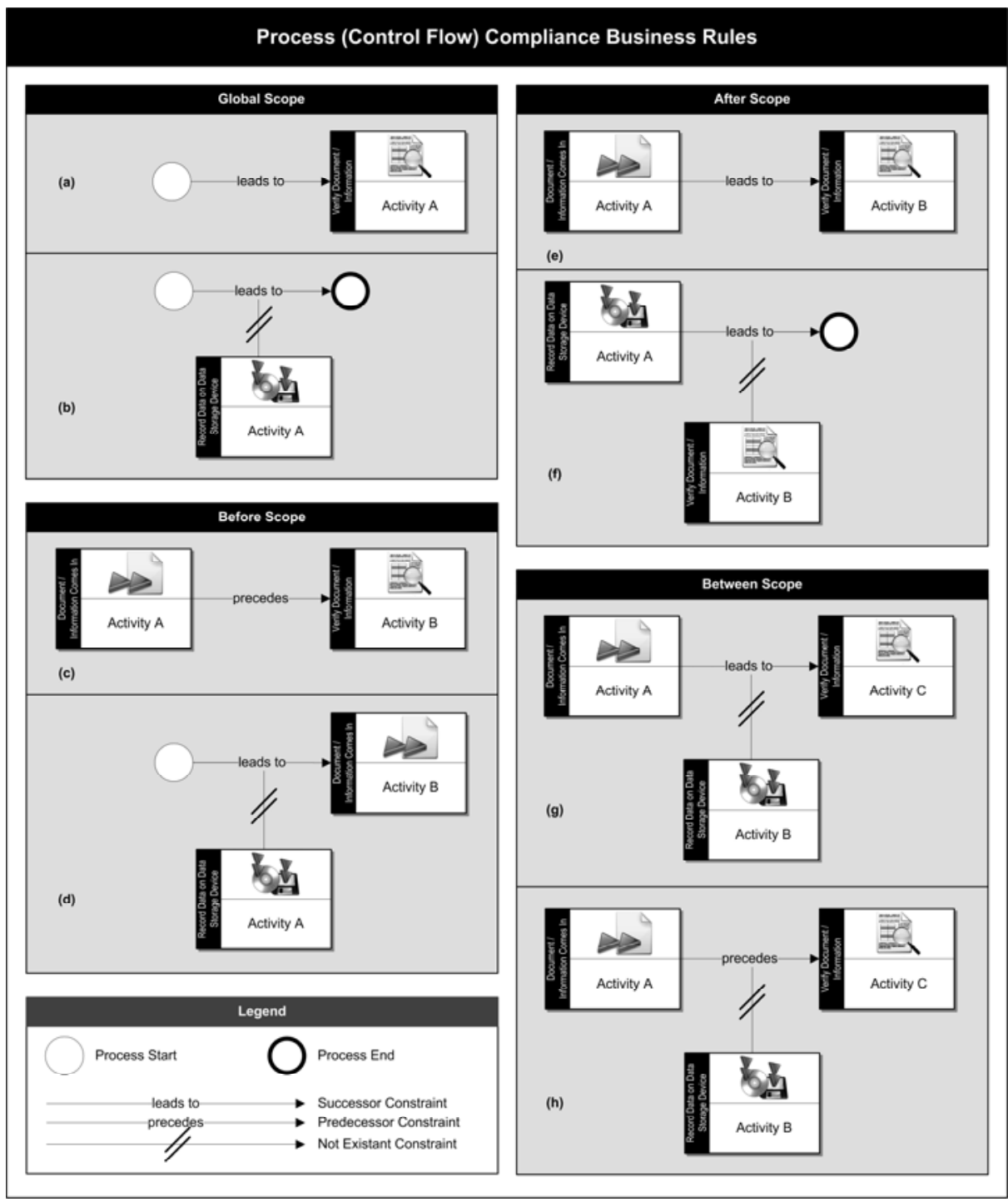

Fig. 2. Basic Control Flow-Related Business Compliance Rules

Figure 3 depicts further, more complex standard business rule patterns. In (k), in contrast to (d), Activity B must not be part of a process in all cases. However, if Activity B is used in a process, Activity A may not be executed before Activity B is finished. In (i) and (j) we suggest the use of a "'Variable Activity" PBB to define direct sequences. In (j) Activity A must be a direct predecessor of Activity B or vice versa Activity B must be a direct successor of Activity A. In (i), through the use of the global scope, we are able to define that Activity A must be the first activity within an entire process. Similarly, one could also predefine the last activity that must be at the 


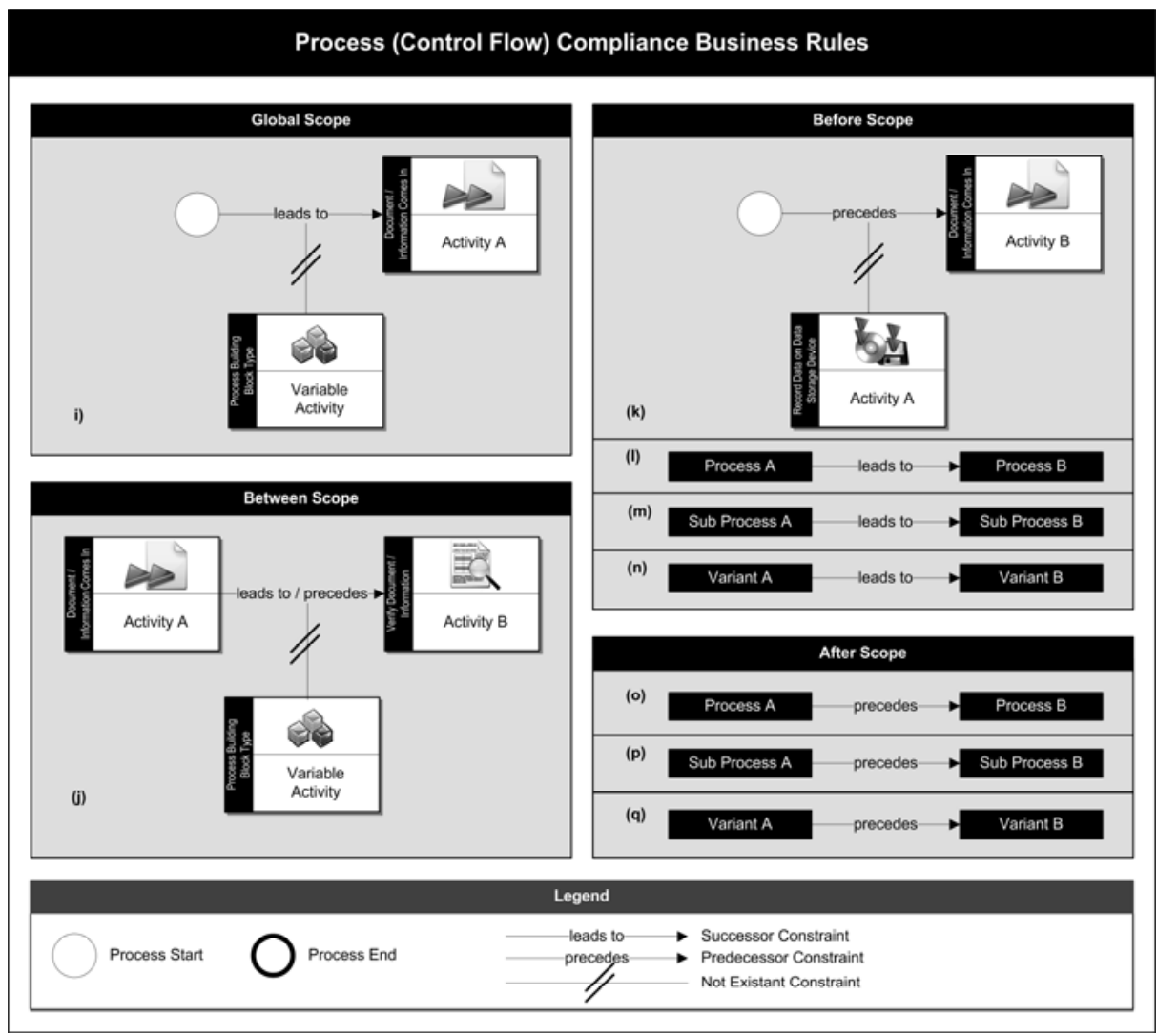

Fig. 3. Complex Control Flow-Related Business Compliance Rules

end of a process. In addition, these rules may not only be applied to activities in the SBPML notation, but also to processes, sub processes and sub process variants $((1)$, $(\mathrm{m}),(\mathrm{n}),(\mathrm{o}),(\mathrm{p}),(\mathrm{q}))$. Through the combination of these simple patterns, more complex patterns can also be derived.

From a resource tag based view with its corresponding organizational view and resource view in the SBPML terminology, further rules can be specified. For resources in terms of the SBPML resource view in general, IT compliance of an IT system, as a resource used during a business process, can be modeled and analyzed, although we will not focus on IT compliance within this article. Focusing on the organizational view of the SBPML terminology, there are two further very common compliance requirements, which need to be captured by business rules. These are the application of a four-eyes-principle (cf. Figure $4(\mathrm{w})$ ), where one person executes Activity A as a "maker" and a second person as the "checker" verifies, if Activity A was done correctly and the aspect of separation of duties for certain activity sequences (cf. Figure 4 (s), (t), (u), (v)). 


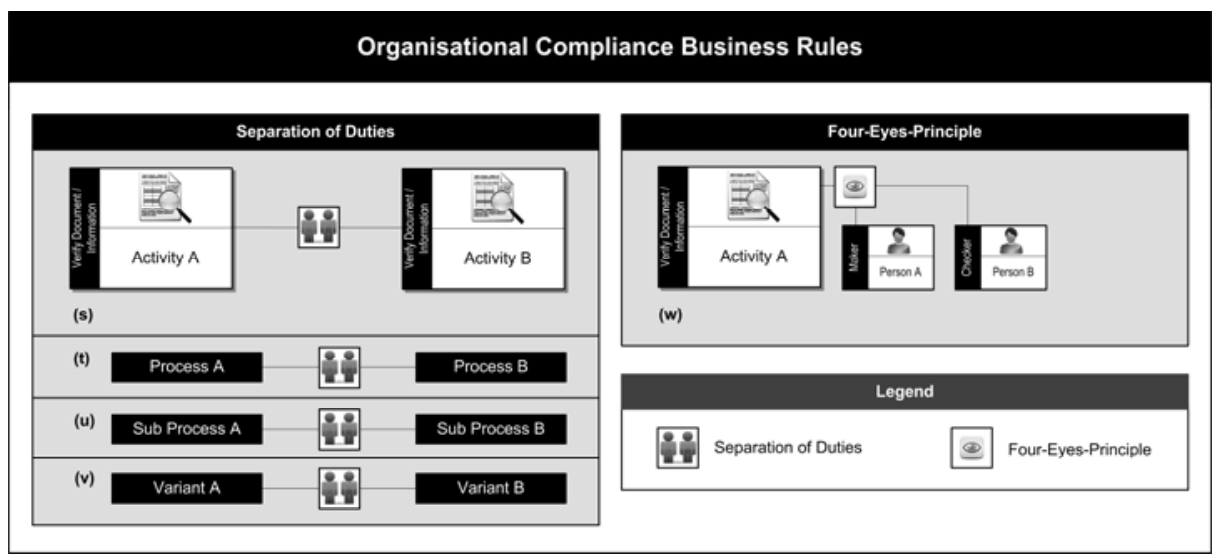

Fig. 4. Resource-Related Business Compliance Rules

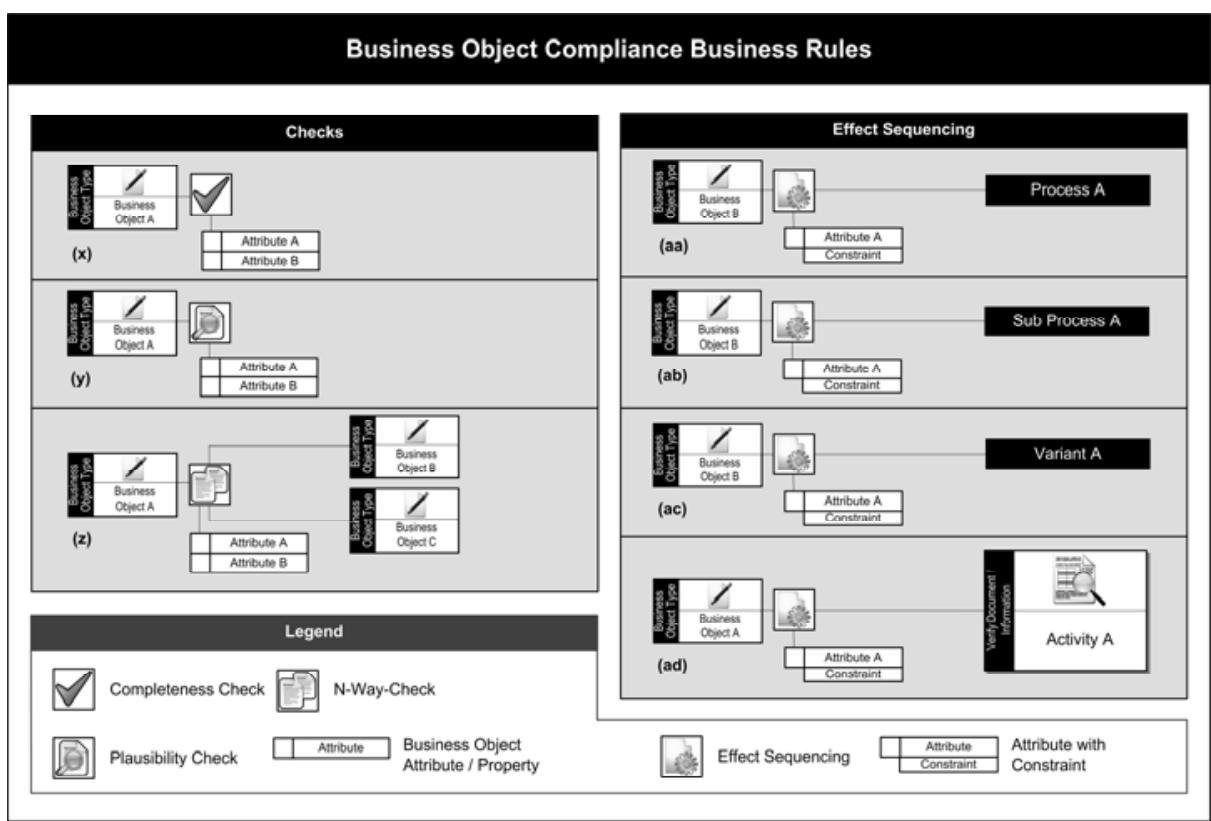

Fig. 5. Data-Related Business Compliance-Rules

Finally, the data tag view with its corresponding business object view in the SBPML terminology requires further types of compliance business rules to be modeled (cf. Figure 5). According to Namiri and Stojanovic (2007), the following data tag rules are important (cf. Figure 6):

a "completeness check" ( $\mathrm{x})$ is important to verify, if all mandatory fields or attributes of a data or business object have been completed (e.g. check if all necessary information is provided in a credit application), 
a "plausibility check" (y) is important to verify, if fields or attributes of a data or business object are plausible (e.g. valid address information),

a "n-way-check" (z) is important to verify, if fields or attributes of data or business objects are the same (e.g. if the birth date is the same on the personal identification card as well as on the credit application).

Besides these business rules, related to certain types of business objects, Zoet et al. (2009) also define "effect sequencing" ((aa), (ab), (ac), (ad)). Effect sequencing describes that business objects, which have certain characteristics, imply further activities to be executed (e.g. credit requests for more than 75,000 € must receive an additional vote inside a bank).

These specified business rules can all be applied to SBPML process models, since the rules only use predefined patterns of activities that are also the basis of the SBPML specification.

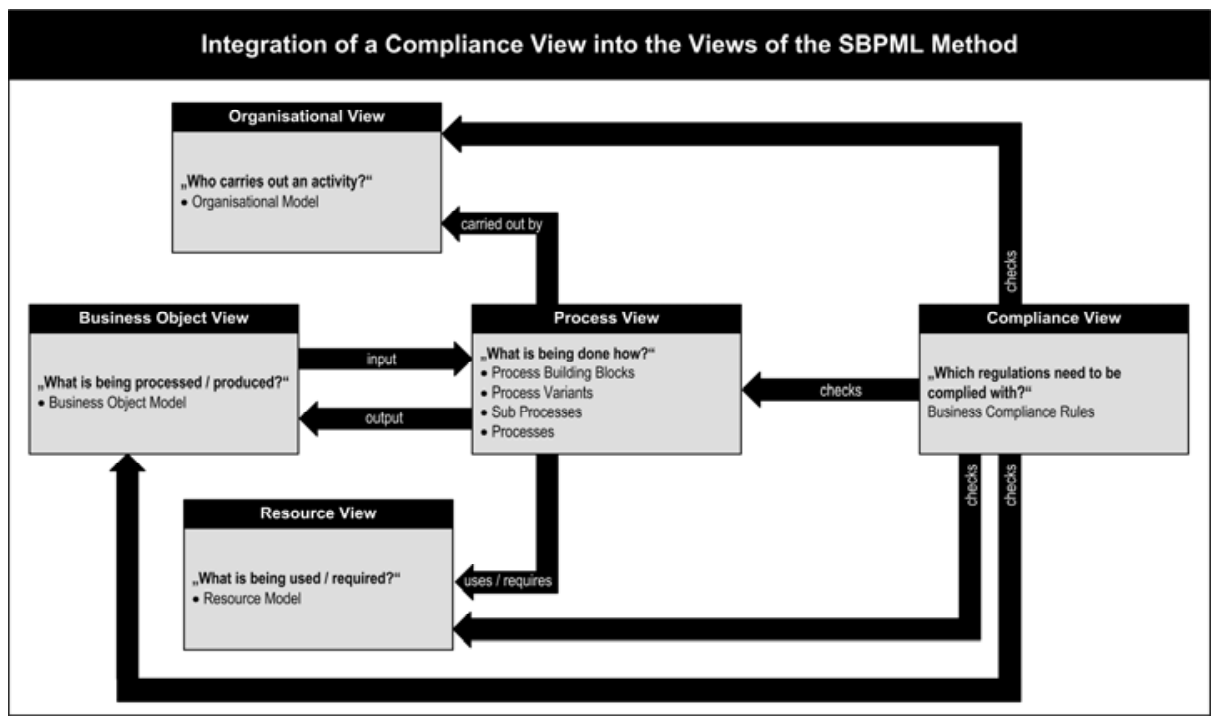

Fig. 6. SBPML Compliance View

Since all these business rules will usually be maintained by a compliance officer, with expertise in the area of compliance management on an enterprise level, as opposed to a process modeler, with expertise in business process management and especially process modeling, we propose to add a compliance view to the SBPML views. This should be linked to all existing views and should give the compliance officer the ability to model, maintain and analyze the compliance business rules with respect to the available elements, used in all other existing views (cf. Figure 6).

\section{Conclusion}

Undoubtedly, the automatic enforcement of compliance and compliant business processes is a very important topic in the financial sector. This is especially due to the 
different scandals, financial crisis and the ongoing regulation debate that will lead to new rules and laws on national and international levels. Therefore, an automated analysis of existing process models is a prerequisite for ensuring BPC. In identifying relevant business rule design patterns, we provide a basis for instantiations, based on the SBPML notation for banks, but also for other notations. The instantiation of the generic rules will allow for an automatic identification of design patterns in process models in banks (cf. Becker et al. 2011) and hence for the discovery of critical compliance issues. At this stage of research, we believe these results to be valid for most purposes in banks. However, in a next step, we are going to further evaluate our findings with the help of various SBPML process models from different banks. Furthermore, by testing the theoretical concepts in practical depth, we may also add new process compliance business rules to our business process compliance pattern library.

\section{References}

Awad, A., Weske, M.: Visualization of Compliance Violation in Business Process Models. In: Proceedings of the 5th Workshop on Business Process Intelligence, Ulm, pp. 1-12 (2009)

Basel Committee on Banking Supervision. Compliance and the Compliance Function in Banks (2004), http: //www.bis.org/publ/bcbs113.pdf?noframes=1 (accessed on 2010-03-04)

Becker, J., Ahrendt, C., Coners, A., Weiß, B., Winkelmann, A.: Business Rule Based Extension of a Semantic Process Modeling Language for Managing Business Process Compliance in the Financial Sector. Lecture Notes in Informatics 175(1), 201-206 (2010a)

Becker, J., Bergener, P., Delfmann, P., Eggert, M., Weiß, B.: Supporting Business Process Compliance in Financial Institutions - A Model-Driven Approach. In: Proceedings of the 10th International Conference on Wirtschaftsinformatik, Zürich, pp. 355-364 (2011)

Becker, J., Bergener, P., Räckers, M., Weiß, B., Winkelmann, A.: Pattern-Based SemiAutomatic Analysis of Weaknesses in Semantic Business Process Models in the Banking Sector. In: Proceedings of the 18th European Conference on Information Systems, Pretoria (2010b)

Becker, J., Weiß, B., Winkelmann, A.: Developing a Business Process Modeling Language for the Banking Sector - A Design Science Approach. In: Proceedings of the 15th Americas Conference on Information Systems, San Francisco, pp. 1-12 (2009)

Becker, J., Weiß, B., Winkelmann, A.: Transferring a Domain-Specific Semantic Process Modeling Language - Findings from Action Research in the Banking Sector. In: Proceedings of the 18th European Conference on Information Systems, Pretoria (2010c)

Becker, J., Weiß, B., Winkelmann, A.: Utility vs. Efforts of Business Process Modeling - An Exploratory Survey in the Financial Sector. In: Proceedings of the Multikonferenz Wirtschaftsinformatik, Göttingen, pp. 41-54 (2010d)

Becker, J., Thome, I., Weiß, B., Winkelmann, A.: Constructing a Semantic Business Process Modelling Language for the Banking Sector - An Evolutionary Dyadic Design Science Approach. Enterprise Modelling and Information Systems Architectures 5(1), 4-25 (2010e)

Business Rules Group. Business Rules Manifesto - The Principles of Rule Independence (2003),

http: / /www. businessrulesgroup.org/brmanifesto/BRManifestB.pdf (accessed on 2010-05-02)

El Kharbili, M., Alwes de Medeiros, A.K., Stein, S., van der Aalst, W.M.P.: Business Process Compliance Checking: Current State and Future Challenges. In: Proceedings of the Modellierung betrieblicher Informationssysteme, Saarbrücken, pp. 107-113 (2008a) 
El Kharbili, M., Stein, S., Markovic, I., Pulvermüller, E.: Towards a Framework for Semantic Business Process Compliance Management. In: Proceedings of the 1st International Workshop on Governance, Risk and Compliance - Applications in Information Systems, Montpellier, pp. 1-15 (2008b)

Endl, R.: Regelbasierte Entwicklung betrieblicher Informationssysteme: Gestaltung flexibler Informationssysteme durch explizite Modellierung der Geschäftslogik," Doctoral Thesis, University of Bern, Bern (2004)

Grob, L., Bensberg, F., Coners, A.: Rule-Based Control of Business Processes - A Process Mining Approach. Wirtschaftsinformatik 50(4), 268-281 (2008)

Hanson, E.N.: Rule Condition Testing and Action Execution in Ariel. In: Proceedings of the ACM-SIGMOD International Conference on Management of Data (1992)

Hay, D., Healy, K.: Defining Business Rules - What are They Really? (2000), http: / /www.businessrulesgroup.org/first_paper/BRGwhatisBR_3ed.pdf (2010-05-02)

Herbst, H., Knolmayer, G.: Ansätze zur Klassifikation von Geschäftsregeln. Wirtschaftsinformatik 37(2), 149-159 (1995)

Hoheseil, H.: Temporale Geschäftsprozessmodellierung, Doctoral Thesis, University of Bern, Bern (2000)

Namiri, K., Stojanovic, N.: Pattern-based Design and Validation of Business Process Compliance. In: On the Move to Meaningful Internet Systems 2007, CoopIS, DOA, ODBASE, GADA, and IS, pp. 59-76 (2007)

Object Management Group, Semantics of Business Vocabulary and Business Rules (SBVR), v1.0 (2006), http: / / www.omg.org/spec/SBVR/1.0/PDF (accessed on 2010-05-02)

Rinderle-Ma, S., Ly, L.T., Dadam, P.: Business Process Compliance. EMISA Forum, 24-29 (2008)

Sadiq, S., Governatori, G., Namiri, K.: Modeling Control Objectives for Business Process Compliance. In: Alonso, G., Dadam, P., Rosemann, M. (eds.) BPM 2007. LNCS, vol. 4714, pp. 149-164. Springer, Heidelberg (2007)

Scheer, A.-W., Werth, D.: Geschäftsprozessmanagement für das Unternehmen von morgen. In: Karagiannis, D., Rieger, B. (eds.) Herausforderungen in der Wirtschaftsinformatik - Festschrift für Hermann Krallmann, Berlin, pp. 49-64 (2006)

Weiß, B., Winkelmann, A.: A Metamodel Based Perspective on the Adaptation of a Process Modeling Language to the Financial Sector. In: Proceedings of the 44th Hawaii International Conference on System Sciences, Koloa (2011)

Wörzberger, R., Kurpick, T., Heer, T.: Checking Correctness and Compliance of Integrated Process Models. In: Proceedings of the 10th International Symposium on Symbolic and Numeric Algorithms for Scientific Computing, Timisoara, pp. 576-583 (2008)

Zoet, M., Welke, R., Versendaal, J., Ravesteyn, P.: Aligning Risk Management and Compliance Considerations with Business Process Development. In: Di Noia, T., Buccafurri, F. (eds.) EC-Web 2009. LNCS, vol. 5692, pp. 157-168. Springer, Heidelberg (2009) 